\title{
PENENTUAN NILAI OPSI SAHAM TIPE EROPA TANPA DIVIDEN DENGAN BLACK-SCHOLES DAN CONSTANT ELASTICITY OF VARIANCE
}

\author{
Yesya Nalendra Reksaningrum, Evy Sulistianingsih, Hendra Perdana
}

\section{INTISARI}

\begin{abstract}
Saham adalah surat berharga yang merupakan instrumen bukti kepemilikan atau penyertaan individu dalam suatu perusahaan. Saham memiliki opsi yang merupakan suatu kontrak antara penjual opsi dengan pembeli opsi, dimana penjual opsi menjamin adanya hak (bukan suatu kewajiban) dari pembeli opsi untuk membeli atau menjual saham tertentu pada waktu dan harga yang telah ditentukan. Sedangkan opsi saham berdasarkan penggunaannya dibagi menjadi tipe Eropa dan tipe Amerika. Terdapat beberapa metode yang dapat digunakan untuk menghitung nilai opsi, diantaranya metode Black-Scholes (BS) dan Constant Elasticity of Variance (CEV). Pada penelitian ini menggunakan metode Black-Scholes dan Constant Elasticity of Variance tanpa dividen dengan menggunakan saham tipe Eropa yaitu saham The Charles Schwab Corporation (SCHW) periode 1 Oktober 2017 hingga 1 Oktober 2018 dengan tingkat suku bunga sebesar 1,25\%. Berdasarkan hasil penelitian, nilai opsi beli saham lebih besar dari nilai opsi yang ditawarkan sehingga disarankan kepada investor untuk membeli saham, sedangkan untuk opsi jual saham, nilai opsi yang dihasilkan lebih kecil daripada nilai opsi yang ditawarkan sehingga disarankan kepada investor untuk menjual saham. Analisis yang dilakukan pada kedua metode tersebut menghasilkan metode terbaik yaitu metode Constant Elasticity of Variance dengan nilai MSE yaitu 0,0080 dan metode BlackScholes yaitu sebesar 0,0708, sehingga untuk nilai opsi beli saham lebih baik menggunakan metode Constant Elasticity of Variance karena nilai MSEnya lebih kecil daripada metode Black-Scholes, sedangkan pada nilai opsi jual saham dengan metode Black-Scholes memiliki nilai MSE lebih kecil yaitu sebesar 0,0062 daripada metode Constant Elasticity of Variance yaitu sebesar 0,0267.
\end{abstract}

Kata Kunci: Black-Scholes, Constant Elasticity of Variance, Opsi Saham

\section{PENDAHULUAN}

Saham adalah surat berharga tanda kepemilikan suatu perusahaan sebagai bukti penyertaan modal [1]. Saham mengenal istilah opsi (option) yang terbagi menjadi dua jenis yaitu opsi jual dan opsi beli. Opsi jual adalah kontrak yang memberikan hak kepada pemegang saham untuk menjual saham pada waktu dan harga yang sudah ditentukan, sedangkan opsi beli merupakan kontrak yang memberikan hak kepada pemegang saham untuk membeli saham pada waktu dan harga yang telah ditentukan. Opsi saham berdasarkan penggunaannya dibagi menjadi dua, yaitu tipe Eropa dan tipe Amerika. Opsi saham tipe Eropa merupakan opsi saham yang dilaksanakan pada waktu yang sudah ditentukan, sedangkan opsi saham tipe Amerika adalah opsi saham yang dilaksanakan pada waktu sebelumnya atau sudah ditentukan [2].

Investasi dalam bentuk saham mempunyai peluang memiliki untung dalam bentuk dividen. Dividen merupakan pembagian keuntungan yang diberikan perusahaan berasal dari keuntungan yang dihasilkan perusahaan [2]. Penentuan opsi saham tipe Eropa tanpa pembayaran dividen dapat dilakukan dengan metode Black-Scholes dan metode Constant Elasticity of Variance. Metode BlackScholes adalah metode penentuan nilai opsi saham yang merupakan metode yang paling terkenal dan banyak digunakan di pasar modal. Metode Black-Scholes hanya dapat digunakan untuk menghitung opsi jual maupun opsi beli tipe Eropa dengan tidak mempertimbangkan pembayaran dividen [3]. Metode Constant Elasticity of Variance merupakan pengembangan metode Black-Scholes untuk harga saham dengan volatilitas stokastik [4]. Metode Constant Elasticity of Variance diketahui sebagai cara untuk mendeskripsikan hubungan kebalikan antara nilai saham dan volatilitas saham [5]. 
Penelitian ini menggunakan data saham The Charles Schwab Corporation (SCHW) periode 1 Oktober 2017 hingga 1 Oktober 2018 dengan asumsi tanpa pembayaran dividen dan tipe opsi yang digunakan adalah opsi tipe Eropa. Penentuan nilai opsi saham dilakukan dengan berbagai macam tahapan, yakni menentukan nilai return dari data saham. Kemudian return data saham yang diperoleh dilakukan uji Normalitas, apabila return data saham berdistribusi Normal, maka dilanjutkan dengan menghitung nilai volatilitas, $\kappa, \beta$ dan nilai opsi saham. Kemudian dilanjutkan dengan menghitung nilai Mean Square Error pada nilai opsi saham yang telah diperoleh. Pada penelitian ini, data saham diolah menggunakan Software Microsoft Excel dan SPSS.

\section{OPSI SAHAM}

Opsi saham merupakan sebuah kontrak yang memberikan hak kepada pemegang saham untuk membeli atau menjual suatu aset tertentu pada harga dan waktu yang telah ditetapkan [6]. Opsi beli saham merupakan hak yang diberikan kepada pemegang opsi saham untuk membeli saham suatu perusahaan dengan harga dan jangka waktu yang telah ditentukan. Harga saham pada waktu jatuh tempo lebih besar dari strike price atau $S_{T}>K$ maka investor akan menggunakan haknya dan mendapatkan keuntungan sebesar $S_{T}>K$, sehingga nilai opsi saham yaitu $S_{T}>K$. Harga saham pada waktu jatuh tempo lebih kecil atau sama dengan strike price maka investor akan memilih untuk tidak menggunakan haknya dan opsi saham beli menjadi tidak bernilai, sehingga nilai opsi saham ialah nol [7]. Nilai opsi saham tipe Eropa dapat dinyatakan sebagai berikut:

$$
C=\operatorname{maks}\left(0, S_{T}-K\right)
$$

Dengan $C$ adalah nilai opsi saham beli tipe Eropa, $K$ adalah strike price, $T$ adalah waktu pada saat jatuh tempo, dan $S_{T}$ adalah harga saham pada waktu jatuh tempo. Opsi jual saham merupakan hak yang diberikan kepada pemegang opsi saham untuk menjual saham suatu perusahaan dengan harga dan jangka waktu yang telah ditentukan. Jika harga saham pada waktu jatuh tempo lebih besar atau sama dengan strike price $S_{T}>K$ maka investor tidak akan menggunakan haknya dan opsi saham menjadi tidak bernilai, sehingga nilai opsi saham adalah nol. Apabila harga saham pada waktu jatuh tempo lebih kecil atau sama dengan strike price atau $S_{T}>K$ maka investor tentu akan memilih menggunakan haknya dan nilai opsi saham jual adalah sebesar $K-S_{T}$ sehingga nilai opsi jual saham tipe eropa dapat dinyatakan sebagai:

$$
P=\operatorname{maks}\left(0, K-S_{T}\right)
$$

\section{RETURN DATA SAHAM}

Return data saham dapat diartikan sebagai tingkat pengembalian atau hasil yang diperoleh akibat melakukan investasi [8]. Sebagai ukuran return majemuk digunakan continuously compounded return. Return jenis ini lebih sering digunakan dalam analisis keuangan karena sifat-sifatnya yang mengikuti distribusi Normal. Continuously compounded return diformulasikan sebagai berikut:

$$
R(t)=\ln \left(\frac{S(t)}{S(t-1)}\right)
$$

\section{VOLATILITAS RETURN DATA SAHAM}

Volatilitas return saham merupakan standar deviasi dari log-return saham pada periode tahunan. Volatilitas ini digunakan untuk mengukur tingkat risiko dari suatu saham. Salah satu metode untuk mengestimasi volatilitas return data saham adalah volatilitas historis, yaitu volatilitas yang dihitung 
berdasarkan pada harga-harga masa lalu. Berikut ini adalah rumus umum dalam menentukan nilai volatilitas [3]:

$$
\sigma=\sqrt{(\text { jumlah hari perdagangan })\left[\frac{\sum_{t=2}^{n}(R(t)-\overline{R(t)})^{2}}{n-1}\right]}
$$

\section{MEAN SQUARE ERROR (MSE)}

$M S E$ merupakan rata-rata selisih kuadrat antara nilai yang diramalkan dan yang diamati. Nilai $M S E$ dapat dihitung dengan persamaan sebagai berikut [9]:

$$
M S E=\sum_{t=1}^{n} \frac{(X(t)-F(t))^{2}}{n}
$$

didefinisikan $X_{t}$ merupakan data aktual pada periode $t$, dalam kasus ini data aktual yang digunakan adalah nilai opsi yang ditawarkan. $F_{t}$ merupakan nilai peramalan pada periode $t$, nilai peramalan yang digunakan adalah nilai opsi dari metode Black-Scholes dan Constant Elasticity of Variance waktu ke-t. Kemudian $n$ adalah banyaknya peramalan yang dalam kasus ini adalah banyaknya $n$ return data saham.

\section{METODE BLACK-SCHOLES}

Metode Black-Scholes pertama kali dikembangkan tahun 1973 oleh Fisher Black dan Myron Scholes dengan tujuan untuk menentukan harga opsi beli dan jual. Metode Black-Scholes hanya dapat dilakukan pada penetapan harga opsi tipe Eropa yang hanya dilaksanakan pada jatuh tempo. Asumsi yang digunakan dalam metode Black-Scholes adalah opsi saham hanya dapat dieksekusi saat waktu jatuh tempo, volatilitas harga saham konstan, tingkat bunga bebas risiko jangka pendek diketahui dan nilainya konstan, dan tidak ada pembayaran dividen [8]. Berikut adalah rumus umum dari metode Black-Scholes.

$$
\begin{gathered}
C_{t}=S_{t} N\left(d_{1}\right)-K \exp (-r(T-t)) N\left(d_{2}\right) \\
P_{t}=K \exp (-r(T-t)) N\left(-d_{2}\right)-S_{t} N\left(-d_{1}\right)
\end{gathered}
$$

dengan:

$$
\begin{aligned}
& d_{1}=\frac{\ln \left(\frac{S_{t}}{K}\right)+(T-t)\left(r+\frac{1}{2} \sigma^{2}\right)}{\sigma \sqrt{T-t}} \\
& d_{2}=\frac{\ln \left(\frac{S_{t}}{K}\right)+(T-t)\left(r-\frac{1}{2} \sigma^{2}\right)}{\sigma \sqrt{T-t}} \\
& N(x)=\int_{-\infty}^{x} \frac{1}{\sqrt{2 \pi}} \exp \left(-\frac{1}{2} z^{2}\right) d z
\end{aligned}
$$

diketahui $t$ adalah waktu, $C_{t}$ adalah nilai opsi beli saham waktu ke- $t, P_{t}$ adalah nilai opsi jual saham waktu ke- $t, S_{t}$ adalah harga saham pada waktu ke- $t, K$ adalah strike price, $r$ adalah suku bunga bebas risiko, $T$ adalah waktu jatuh tempo, dan $\sigma$ merupakan nilai volatilitas. 


\section{METODE CONSTANT ELASTICITY OF VARIANCE}

Metode Constant Elasticity of Variance pertama kali diperkenalkan oleh John Cox dan Stephen Ross pada tahun 1976 yang merupakan perkembangan dari metode Black-Scholes. Keunggulan metode Constant Elasticity of Variance yaitu merupakan metode yang paling jelas dalam permasalahan keuangan dan mempunyai waran yang lebih panjang dari waktu ke waktu [10]. Rumus umum metode Constant Elasticity of Variance tanpa pembayaran dividen adalah sebagai berikut:

$$
\begin{aligned}
C_{t} & =\left(S_{t}-K+r K(T-t)\right) N\left(\frac{\kappa\left(\frac{S_{t}-K}{K}\right)}{\sigma \sqrt{T-t}}\right)+\kappa \sigma \sqrt{T-t}\left(\frac{\beta S_{t}+(4-\beta) K}{4}\right) N\left(\frac{\kappa\left(\frac{S_{t}-K}{K}\right)}{\sigma \sqrt{T-t}}\right) \\
P_{t} & =\left(S_{t}-K+r K(T-t)\right) N\left(\frac{\kappa\left(\frac{S_{t}-K}{K}\right)}{\sigma \sqrt{T-t}}\right)+\kappa \sigma \sqrt{T-t}\left(\frac{\beta S_{t}+(4-\beta) K}{4}\right) N\left(\frac{\kappa\left(\frac{S_{t}-K}{K}\right)}{\sigma \sqrt{T-t}}\right) \\
& +K \exp (-r(T-t))-S_{t}
\end{aligned}
$$

\section{STUDI KASUS}

Jenis data yang digunakan dalam penelitian ini adalah data sekunder yang diperoleh dari Yahoo Finance (sumber: yahoo finance). Data tersebut merupakan data saham The Charles Schwab Corporation (SCHW) periode 1 Oktober 2017 hingga 1 Oktober 2018 dan tingkat suku bunga sebesar 1,25\% (sumber: fxstreet), sedangkan waktu jatuh tempo opsi saham yaitu 33 hari (2 November 2018). Tahapan dalam menghitung nilai opsi dengan metode Black-Scholes dan Constant Elasticity of Variance yaitu menghitung nilai return data saham. Return data saham yang digunakan harus berdistribusi Normal. Sehingga sebelum mencari volatilitas, dilakukan uji normalitas terlebih dahulu terhadap return data saham.

\section{UJI NORMALITAS RETURN DATA SAHAM}

Kenormalan terhadap return data saham adalah syarat dalam melakukan pemetodean Black-Scholes dan Constant Elasticity of Variance.

Hipotesis dalam uji normalitas return data saham adalah sebagai berikut:

$H_{0}:$ Return data saham berdistribusi Normal

$H_{1}:$ Return data saham tidak berdistribusi Normal

Statistik uji yang digunakan pada uji Kolmogorov-Smirnov adalah $H_{0}$ ditolak jika Asymp.sig $<\alpha$.

\begin{tabular}{lc} 
Tabel 1. Uji Normalitas Return Data Saham \\
\hline $\mathrm{N}$ & 250 \\
Mean & 0,0004 \\
Std. Deviasi & 0,0156 \\
Asymp.sig & 0,1590 \\
\hline
\end{tabular}

Hasil uji Normalitas yang dilakukan dengan SPSS pada return data saham dengan Asymp.sig > Alpha yaitu dengan nilai Asymp.sig sebesar 0,159 dan nilai Alpha sebesar 0,05 sehingga dapat disimpulkan bahwa return data saham berdistribusi Normal. 


\section{VOLATILITAS RETURN DATA SAHAM}

Nilai volatilits dihitung dengan rumus sebagai berikut:

$$
\begin{aligned}
\sigma & =\sqrt{(\text { jumlahhari perdagangan })\left[\frac{\sum_{t=1}^{n}(R(t)-\overline{R(t)})^{2}}{n-1}\right]} \\
& =\sqrt{(251) \frac{\sum_{t=1}^{250}(R(t)-\overline{R(t)})^{2}}{250-1}} \\
& =0,2475
\end{aligned}
$$

Berdasarkan data saham SCHW selama tahun 2017 hingga 2018, diperoleh volatilitas dari return data saham yaitu sebesar 0,2475 .

\section{MENENTUKAN NILAI OPSI SAHAM DENGAN BLACK-SCHOLES DAN CONSTANT ELASTICITY OF VARIANCE}

Untuk menentukan nilai opsi saham pada metode Black-Scholes dan Constant Elasticity of Variance dapat dilihat pada penjelasan berikut.

a. Opsi Beli Saham

Diketahui nilai volatilitas harga saham $S C H W$ adalah 0,2475 , tingkat suku bunga pada saat itu adalah $1,25 \%$, dan waktu jatuh tempo opsi saham sampai tanggal 2 November 2018 (umur surat kontrak opsi saham 33 hari). Jika hasil perhitungan lebih besar dari nilai opsi yang ditawarkan, maka tindakan yang sebaiknya dilakukan investor adalah membeli opsi saham. Sebaliknya, apabila hasil perhitungan lebih kecil dari nilai opsi yang ditawarkan, maka investor disarankan untuk menjual opsi saham. Nilai opsi beli saham dapat dilihat pada tabel 2 .

Tabel 2. Nilai Opsi Beli Saham

\begin{tabular}{cccccc}
\hline $\begin{array}{c}\text { Harga } \\
\text { Eksekusi }\end{array}$ & $\begin{array}{c}\text { Opsi yang } \\
\text { ditawarkan }\end{array}$ & $\begin{array}{c}\text { Opsi } \\
\text { Beli } \boldsymbol{B} \boldsymbol{S}\end{array}$ & Saran & $\begin{array}{c}\text { Opsi Beli } \\
\boldsymbol{C} \boldsymbol{E} \boldsymbol{V}\end{array}$ & Saran \\
\hline 40,5 & 2,75 & 4,4666 & Beli & 2,9736 & Beli \\
41,5 & 2,90 & 3,6471 & Beli & 2,4419 & Jual \\
42,0 & 1,74 & 3,2658 & Beli & 2,1810 & Beli \\
42,5 & 1,47 & 2,9058 & Beli & 1,9234 & Beli \\
43,0 & 1,30 & 2,5686 & Beli & 1,6688 & Beli \\
43,5 & 0,85 & 2,2553 & Beli & 1,4172 & Beli \\
44,0 & 0,51 & 1,9666 & Beli & 1,1684 & Beli \\
44,5 & 0,45 & 1,7028 & Beli & 0,9224 & Beli \\
45,0 & 0,30 & 1,4640 & Beli & 0,6792 & Beli \\
45,5 & 0,17 & 1,2496 & Beli & 0,4385 & Beli \\
\hline
\end{tabular}

b. Opsi Jual Saham

Diketahui nilai volatilitas harga saham $S C H W$ adalah 0,2475 dengan tingkat suku bunga pada saat itu adalah 1,25\%, dan waktu jatuh tempo opsi saham sampai tanggal 2 November 2018 
(umur surat kontrak opsi saham 33 hari). Jika hasil perhitungan lebih besar dari nilai opsi yang ditawarkan, maka tindakan yang sebaiknya dilakukan investor atau pemegang saham adalah membeli opsi saham. Sebaliknya, apabila hasil perhitungan lebih kecil dari nilai opsi yang ditawarkan, maka investor disarankan untuk menjual opsi saham. Tabel 3 menunjukkan nilai opsi jual saham yang sudah dihitung menggunakan Black-Scholes dan Constant Elasticity of Variance.

Tabel 3. Nilai Opsi Jual Saham

\begin{tabular}{cccccc}
\hline $\begin{array}{c}\text { Harga } \\
\text { Eksekusi }\end{array}$ & $\begin{array}{c}\text { Opsi yang } \\
\text { ditawarkan }\end{array}$ & $\begin{array}{c}\text { Opsi } \\
\text { Jual } \boldsymbol{B} \boldsymbol{S}\end{array}$ & Saran & $\begin{array}{c}\text { Opsi } \\
\text { Jual } \boldsymbol{C E} \boldsymbol{V}\end{array}$ & Saran \\
\hline 40,0 & 0,20 & 0,1952 & Jual & 0 & Jual \\
41,0 & 0,34 & 0,3407 & Beli & 0 & Jual \\
41,5 & 0,55 & 0,4390 & Jual & 0 & Jual \\
42,0 & 0,65 & 0,5568 & Jual & 0 & Jual \\
42,5 & 0,94 & 0,6961 & Jual & 0 & Jual \\
43,0 & 0,98 & 0,8580 & Jual & 0 & Jual \\
43,5 & 1,02 & 1,0439 & Beli & 0,2057 & Jual \\
44,0 & 1,80 & 1,2544 & Jual & 0,4562 & Jual \\
44,5 & 0,50 & 1,4898 & Beli & 0,7094 & Beli \\
45,0 & 2,16 & 1,7501 & Jual & 0,9653 & Jual \\
\hline
\end{tabular}

\section{PERBANDINGAN NILAI OPSI SAHAM METODE BLACK-SCHOLES DAN CONSTANT ELASTICITY OF VARIANCE}

Dalam perbandingan nilai opsi saham menggunakan metode Black-Scholes dan metode Constant Elasticity of Variance, nilai MSE menjadi tolak ukur dalam menentukan metode terbaik dengan melihat nilai $M S E$ yang paling kecil. Pada Tabel 4 dapat dilihat bahwa nilai MSE pada metode Constant Elasticity of Variance lebih kecil dibandingkan dengan nilai MSE pada metode BlackScholes. Sehingga dapat disimpulkan bahwa metode Constant Elasticity of Variance lebih baik dalam menentukan nilai opsi beli saham.

Tabel 4. MSE Nilai Opsi Beli Saham

\begin{tabular}{ccccc}
\hline $\begin{array}{c}\text { Opsi yang } \\
\text { ditawarkan }\end{array}$ & $\begin{array}{c}\text { Opsi } \\
\text { Beli } \boldsymbol{B S} \boldsymbol{S}\end{array}$ & $\begin{array}{c}\text { Opsi } \\
\text { Beli } \boldsymbol{C} \boldsymbol{E} \boldsymbol{V}\end{array}$ & $\begin{array}{c}\boldsymbol{S} \boldsymbol{B} \boldsymbol{B} \\
\boldsymbol{B} \boldsymbol{C} \boldsymbol{E} \boldsymbol{V}\end{array}$ \\
\hline 2,75 & 4,4666 & 2,9736 & 2,9467 & 0,0500 \\
2,90 & 3,6471 & 2,4419 & 0,5582 & 0,2099 \\
1,74 & 3,2658 & 2,1810 & 2,3281 & 0,1945 \\
1,47 & 2,9058 & 1,9234 & 2,0615 & 0,2056 \\
1,30 & 2,5686 & 1,6688 & 1,6093 & 0,1360 \\
0,85 & 2,2553 & 1,4172 & 1,9749 & 0,3217 \\
0,51 & 1,9666 & 1,1684 & 2,1217 & 0,4335 \\
0,45 & 1,7028 & 0,9224 & 1,5695 & 0,2232 \\
0,30 & 1,4640 & 0,6792 & 1,3549 & 0,1438 \\
0,17 & 1,2496 & 0,4385 & 1,1655 & 0,0721 \\
\hline & & $\boldsymbol{M S E}$ & $\mathbf{0 , 0 7 0 8}$ & $\mathbf{0 , 0 0 8 0}$ \\
\hline
\end{tabular}

Perbandingan nilai opsi jual saham dapat dilihat pada Tabel 5 dengan melihat nilai MSEnya, metode Black-Scholes merupakan metode yang lebih baik untuk menentukan nilai opsi jual saham dibandingkan dengan metode Constant Elasticity of Variance. 
Tabel 5. MSE Nilai Opsi Jual Saham

\begin{tabular}{ccccc}
\hline $\begin{array}{c}\text { Opsi yang } \\
\text { ditawarkan }\end{array}$ & $\begin{array}{c}\text { Opsi } \\
\text { Jual } \boldsymbol{B S}\end{array}$ & $\begin{array}{c}\text { Opsi } \\
\text { Jual } \boldsymbol{C E} \boldsymbol{V}\end{array}$ & $\begin{array}{c}\text { SE } \\
\boldsymbol{B S}\end{array}$ & $\begin{array}{c}\text { SE } \\
\boldsymbol{C E} \boldsymbol{V}\end{array}$ \\
\hline 0,20 & 0,1952 & 0 & $2,3 \times 10^{-5}$ & 0,0400 \\
0,34 & 0,3407 & 0 & $4,9 \times 10^{-7}$ & 0,1156 \\
0,55 & 0,439 & 0 & 0,0123 & 0,3025 \\
0,65 & 0,5568 & 0 & 0,0087 & 0,4225 \\
0,94 & 0,6961 & 0 & 0,0595 & 0,8836 \\
0,98 & 0,858 & 0 & 0,0149 & 0,9604 \\
1,02 & 1,0439 & 0,2057 & 0,0006 & 0,6631 \\
1,80 & 1,2544 & 0,4562 & 0,2977 & 1,8058 \\
0,50 & 1,4898 & 0,7094 & 0,9797 & 0,0438 \\
2,16 & 1,7501 & 0,9653 & 0,1680 & 1,4273 \\
\hline & & $\mathbf{M S E}$ & $\mathbf{0 , 0 0 6 2}$ & $\mathbf{0 , 0 2 6 7}$ \\
\hline
\end{tabular}

\section{KESIMPULAN}

Setelah membahas mengenai penentuan nilai opsi saham tipe Eropa tanpa dividen dengan metode Black-Scholes dan Constant Elasticity of Variance pada data saham The Carles Schwab Corporation $(S C H W)$ serta menganalisis perbandingan antara kedua metode tersebut, maka diperoleh kesimpulan sebagai berikut:

1. Nilai opsi saham pada metode Black-Scholes adalah sebesar 4,4666 untuk opsi saham beli dengan strike price sebesar 40,5 dan 0,1952 untuk opsi jual saham dengan strike price sebesar 40. Kemudian, untuk nilai opsi beli saham dan opsi jual saham metode Constant Elasticity of Variance ialah sebesar 2,9736 dengan strike price 40,5 dan 0 dengan strike price 40.

2. Perolehan nilai MSE pada opsi beli saham dan opsi jual saham metode Black-Scholes adalah sebesar 0,0708 dan 0,0062, sedangkan untuk nilai MSE metode Constant Elasticity of Variance yaitu sebesar 0,0080 untuk opsi beli saham dan sebesar 0,0267 untuk opsi jual saham. Dari hasil perolehan MSE masing-masing metode dapat dilihat bahwa nilai MSE metode Constant Elasticity of Variance lebih kecil dibandingkan dengan metode Black-Scholes untuk nilai opsi beli saham, sehingga metode Constant Elasticity of Variance lebih baik digunakan dalam penentuan nilai opsi beli saham tipe Eropa tanpa dividen. Sedangkan untuk nilai opsi jual saham lebih baik diperoleh menggunakan metode Black-Scholes karena nilai MSE Black-Scholes lebih kecil dibandingkan metode Constant Elasticity of Variance.

\section{DAFTAR PUSTAKA}

[1] Akbar AR, Hidayat RR, Sulasmiyati S. Analisis Kinerja Investasi Saham Dengan Metode Sharpe Model di Beberapa Bursa Efek Asean (Studi Pasar Modal Pada Filipina, Indonesia, Malaysia, Singapura, dan Thailand Tahun 2012-2015). Jurnal Administrasi Bisnis (JAB). 2017; 50(6).

[2] Kurniawan OTS. Penentuan Harga Opsi Saham dengan Menggunakan Metode Beda Hingga Crank-Nicholson (C-N). e-Jurnal Matematika. 2012; 1(1):20-24.

[3] Hull JC. Option, Futures, and Other Derivates (7th Ed). New Jersey: Pearson Prentice Hall; 2009.

[4] Beckers S. The Constant Elasticity of Variance Model and Its Implication For Option Pricing. The Journal of Finance. 1980; 35(3):661-673. 
[5] Randal J. The Constant Elasticity of Variance Option Pricing Model. Master of Science in Statistics and Operations Research; 1998.

[6] Susandy G. Analisis Perbandingan Nilai Opsi Saham dan Opsi Valas dengan Menggunakan Model Black-Scholes (Studi Simulasi 6 Saham di Bursa Efek Jakarta dan 6 Valas di Bank Indonesia). Jurnal Dimensia. 2006; 3(2).

[7] Higham DJ. An Introduction to Financial Option Valuation. Cambridge: University Press; 2004.

[8] Mooy MN, Rusgiyono A, Rahmawati R. Penentuan Harga Opsi Put dan Call Tipe Eropa Terhadap Saham Menggunakan Model Black-Scholes. Jurnal Gaussian. 2017; 6(3):407-417.

[9] Margi K, Pendawa S. Analisa dan Penerapan Metode Single Exponential Smoothing untuk Prediksi Penjualan Pada Periode Tertentu (Studi Kasus: PT. Media Cemara Kreasi). Prosiding SNATIF. 2015; 2.

[10] Lo CF, Yuen PH. Constant Elasticity of Variance Option Pricing Model With Time-Dependent Parameters. International Journal of Theoritical adn Applied Finance. 2000; 3(4):661-674.

$\begin{array}{ll}\text { YESYA NALENDRA R } & \begin{array}{c}\text { : Jurusan Matematika FMIPA UNTAN, Pontianak } \\ \text { yesanalendra@ gmail.com }\end{array} \\ \text { EVY SULISTIANINGSIH } & \begin{array}{c}\text { : Jurusan Matematika FMIPA UNTAN, Pontianak } \\ \text { evysulistianingsih@ math.untan.ac.id }\end{array} \\ \text { HENDRA PERDANA } & \begin{array}{l}\text { Jurusan Matematika FMIPA UNTAN, Pontianak } \\ \text { hendra.perdana@ math.untan.ac.id }\end{array}\end{array}$

